\title{
TAUBERIAN THEOREMS UNDER STATISTICALLY NÖRLUND-CESÁRO SUMMABILITY METHOD
}

\author{
NAIM L. BRAHA
}

Abstract. Let $\left(p_{n}\right)$ and $\left(q_{n}\right)$ be any two non-negative real sequences with

$$
R_{n}:=\sum_{k=0}^{n} p_{k} q_{n-k} \neq 0(n \in \mathbb{N}) .
$$

And $C_{n}^{1}-$ Cesáro summability method. Let $\left(x_{n}\right)$ be a sequence of real or complex numbers and set

$$
N_{p, q}^{n} C_{n}^{1}:=\frac{1}{R_{n}} \sum_{k=0}^{n} p_{k} q_{n-k} \frac{1}{k+1} \sum_{v=0}^{k} x_{v}
$$

for $n \in \mathbb{N}$. In this paper, we present necessary and sufficient conditions under which the existence of the limit $s t-\lim _{n \rightarrow \infty} x_{n}=L$ follows from that of $s t-\lim _{n \rightarrow \infty} N_{p, q}^{n} C_{n}^{1}=L$. These conditions are one-sided or two-sided if $\left(x_{n}\right)$ is a sequence of real or complex numbers, respectively.

Mathematics subject classification (2010): 40G15, 41A36.

Keywords and phrases: Generalized Nörlund-Cesáro summability method, one-sided and two-sided Tauberian conditions, statistical convergence.

\section{REFERENCES}

[1] Borwein, D., On products of sequences, J. London Math. Soc. 33, 352-357 (1958).

[2] BRAHA, N.L., Tauberian conditions under which $\lambda$-statistical convergence follows from statistical summability $(V, \lambda)$, Miskolc Math. Notes. 16(2), 695-703 (2015).

[3] BRAha, N.L., Tauberian Theorems under Nörlund-Cesáro summability methods, Current Topics in Summability Theory and Applications, editors, Hemen Dutta and Billy E. Rhoades, Springer, (357411), 2016.

[4] Kiesel, R., General Nörlund transforms and power series methods, Math. Z. 214(2), 273-286 (1993).

[5] Kiesel, R., StadtmülleR, U., Tauberian- and convexity theorems for certain $(N, p, q)$-means, Canad. J. Math. 46(5), 982-994 (1994).

[6] StadtmüLler, U., TALI, A., On certain families of generalized Nörlund methods and power series methods, J. Math. Anal. Appl. 238(1), 44-66 (1999). 